\title{
Foundations or Bridges? A review of J. E. King's The microfoundations delusion: metaphor and dogma in the history of macroeconomics. Edward Elgar, 2012, 304 pp.
}

\author{
KEVIN D. HOOVER \\ Duke University
}

J. E. King has written a timely book. The dominant mainstream of the economics profession is deeply committed to the notion that macroeconomics requires microfoundations; yet there has not been a careful book-length examination of this dogma since Maarten Janssen's (1993) methodological and James Hartley's (1999) more historical accounts. King's book is valuable, as it surveys both the microfoundations dogma itself and the methodological and philosophical accounts of reductionism and methodological individualism that are often thought to ground it. Its strength lies in the fact that King has read very widely and provides usable capsule summaries of a huge range of views of economists, philosophers, and social scientists facing cognate issues in their own disciplines.

\section{I}

Although foreshadowed earlier, a clear distinction between microeconomics and macroeconomics is a product of the 1930s. The terms were coined by Ragnar Frisch and spread through the newly formed Econometric Society. The relationship of John Maynard Keynes to this distinction-Keynes in fact used neither term-is more equivocal than the folk wisdom of economists would suggest. The nature of the relationship between micro- and macroeconomics was considered to be a critical issue from the outset, having been discussed by Frisch (1933) himself. (Frisch argued that a successful microanalysis must be grounded in a background macro analysis.) Leontief (1936) attacked Keynes's General theory of employment, interest, and money (1936) on the ground that his aggregate analysis violated basic principles of microeconomics.

There is considerable common ground among economists. No one really denies that the economy is a collection of individuals and that macroeconomics uses categories and relations that are not, on their 
face, about particular individuals. The question about the relationship of macro- to microeconomics is, then, immediate.

One frequent answer that appeals to many economists is that microeconomics underpins, lies behind or below macroeconomics and that it accounts for the properties, limitations, and success of macroeconomics and, even, that microeconomics may be adequate on its own-that is, macroeconomics may be dispensable or even illegitimate. This is the microfoundational impulse.

A second alternative is to assert than macroeconomics is autonomous from microeconomics-though whether this is a conceptual, ontological, epistemological, explanatory, or pragmatic autonomy is a point of contention. Some hold that the macroeconomic may influence the microeconomic, which amounts to a denial or at least to a tempering of the microfoundational impulse.

A third possibility is that micro- and macroeconomics are relatively independent and that, while the connection between them is interesting, it is not scientifically essential.

King is clearly opposed to the first position and somewhat straddles the second and third. There is no pose of historical neutrality. His book is a systematic attack on the first view:

the microfoundations dogma has had, and continues to have, a large and pernicious effect: directly on academic economics, and indirectly on economic policy and public discourse on economic issues (p. 10).

I am sympathetic. A large part of my professional life has been devoted to considering the history and the methodological issues surrounding the microfoundations of macroeconomics, and I typically come down close to King's position. But although I doubt that historians of economics can or should maintain intellectual neutrality, it is a virtue to strive for interpretive charity: try to grasp the best case for views that we oppose and let normative judgments arise from the interaction of our inevitably non-neutral perspective with a fair-minded and even-handed presentation of the facts and arguments, rather than dispensing labels (good guys/bad guys, insightful/benighted, consistent/inconsistent) according to whether or not historical characters conform to our own views. We cannot help making ex post evaluations, but the best history is not about those evaluations but 
about understanding how and why people believed and acted as they did and how we got to where are now.

\section{II}

Although King's survey reaches back into the 1930s, he concludes that microfoundations is a product of the 1970s, first reaching its full expression in the real-business-cycle models of the early 1980s. He identifies microfoundations with the representative-agent rationalexpectations model. The core of his book is an historical-or, at least, chronological-account of how that approach came to dominate macroeconomics and a case for why the approach itself is wrong.

King's argument begins with a methodological or philosophical treatment of the issue. He argues that advocates of microfoundations maintain a reductionist thesis that ignores the fallacy of compositioni.e., it ignores that the whole is greater than the sum of its parts. Second, he maintains that macroeconomics conditions microeconomics-that is, there is downward causation. "Downward" is to King really a misnomer, since (note the subtitle of the book) he sees history as guided by a poor metaphor: foundations imply microeconomics is more basic than macroeconomics. In contrast, King sees the relationship more as a bridge, a buttress, stepping stones, or some other horizontal, rather than vertical, relationship.

King is an historian, not a philosopher. His admirable canvass of a variety of relevant philosophical issues (e.g., reductionism, methodological individualism, the role of metaphor in science) does not amount to a compelling analytical account. Rather he simply endorses the views that support his starting position. He maintains that anyone who acknowledges emergence or the fallacy of composition, for example, opposes-or should oppose, if consistent-methodological individualism and microfoundations.

Treating the fallacy of composition, as King does, as equivalent to the whole being greater than the sum of its parts leaves unanalyzed just what the operation of summing amounts to. No reductionist denies (a) that a car is not just the mereological sum of its parts, but must be assembled correctly to be a car, and therefore (b) that distinctive car properties are fully explained, and ontologically depend on, the parts and their relationships. As a result, (i) the emergence of car properties is not mysterious or ineffable but predictable, and (ii) the car's 
characteristics, as opposed to the parts and their relationships, are at least in principle dispensable.

There are varieties of anti-reductionists. None needs to deny that it is always legitimate to ask what explains a macro-phenomenon nor that sometimes wholes can be explained by analysis into parts and the relationships among them. If reductionists are too enthusiastic in elevating and projecting successful reductive explanations into fundamental ontological and epistemological claims that outstrip their actual practical explanatory achievements, the anti-reductionist need not fear that any successful reductive explanation is a step on the slippery slope that entails commitment to reduction in principle to individual agents (or subatomic particles!).

The anti-reductionist wants at least to keep the door open for unpredictable emergence. King's all or nothing approach-to admit a fallacy of composition is to reject reductionism-is hard to sustain with his own concrete examples. Keynes's income multiplier is held up as the paradigm of the fallacy of composition. Yet, nominal GDP is, as an accounting fact, the sum of individual incomes, and the multiplier process can be explained step by step completely in terms of the behavior of individuals, only adding up the incomes in the end to get aggregate GDP. The fallacy of composition is that the attempt of an individual to save, which ceteris paribus would increase his own savings, will not result in net aggregate savings if all individuals try to save simultaneously. There is no anti-reductionist mystery here: we can trace out the process individual by individual, and the aggregate result is predictable on that basis.

\section{III}

King's emphasis on the metaphor of foundations (e.g., the foundations of a building on which the higher floors are built) and on the importance of metaphor in science (more asserted than demonstrated or analyzed) forces him into a narrow historiographical box. The problem is that he adopts-if the term is not too oxymoronic-a "metaphorical literalism". Only those who view microeconomics as foundational in the sense that macroeconomics is supposed to be fully derivable from microeconomics and that macroeconomics is completely dispensable count as endorsing the metaphor of foundations and thus as supporting a microfoundational program. It is for this reason that King sees true microfoundations as entering macroeconomics only in the mid-1970s. 
But metaphors are figures of speech, not rigid logical or conceptual templates. They are often taken loosely, incompletely, and inconsistently-that is the nature of all figures of speech. Even technical terms and concepts do not have absolutely precise meanings that remain stable among individuals or over time. Inconsistency mongers never want for trade.

My own preference is to define microfoundations-as I believe the economics profession broadly does-as involved whenever microeconomics is held to be ontologically, epistemologically, or explanatorily more basic than macroeconomics, such that persuasive, sound, reliable, robust macroeconomics must make explicit reference to microeconomics. Taken this way, microfoundations has existed since the 1930s, in practice if not in name.

To see the difference, note that King rejects the view that Lawrence Klein was a true microfoundationalist in the 1940s, because he wanted to treat both microeconomics and macroeconomics as valid approaches and to establish a consistent connection between them. King sees this as a horizontal relationship as opposed to the vertical one implied in the foundationalist metaphor. But I see Klein as having an explicit microfoundational program, since in his Keynesian revolution (1947) he expresses grave doubts as to whether Keynes's macroeconomics can be secure or empirically useful without establishing its connection to microeconomics. Later he adopts the position that we should never stop looking for reductionist explanations of aggregates. His preferred methodology is thus one of disaggregating and adding to the complexity of models as far as data allow and of getting better data as soon as possible.

On my view, microfoundations has been a central issue in macroeconomics from an early date, and there are multiple microfoundational programs distinguished by differing conceptions of the micro/macro relationship and various pragmatic and theoretical goals (Hoover 2012). My position resolves some puzzles thrown up by King's account. For example, he questions whether there really ever was a general-equilibrium microfoundational program (p. 94). The term "microfoundations" received an enormous boost from E. Roy Weintraub's article "The microfoundations of macroeconomics" (1977) and book Microfoundations (1979), which were devoted almost exclusively to such a program. King can question its existence only 
because of the narrow way in which he has framed what can count as a microfoundational program.

\section{IV}

King's historiographic method does not serve him well. It amounts to a comprehensive survey in which schools and individuals are scored for their degree of conformity with the maintained right answer-namely, that microfoundations is a wrong and pernicious doctrine. For example, he notes that the new Keynesian macroeconomics was initially resistant to the representative-agent approach (score one for them), but inexplicably abandoned it (score one against). It would have been better to try to work out why they abandoned their initial position than to simply note their fall in the league table. Some post-Keynesians (King regards himself as one) are credited as anti-microfoundationalists; others are vilified for drinking the Kool Aid, maintaining that microfoundations are the right idea, but asserting that "ours are better than yours" (p. 150). It would yield greater insight to try, charitably, to grasp why different economists thought that their preferred answers made sense: What was their problem situation-both substantively and sociologically? How did their thinking develop? Why were they persuaded? The key here is not to seek out inconsistency and root out deviance, but to exercise interpretive charity. Don Patinkin used to say that historical interpretation should follow a regression model in which a thinker is credited with the views that constitute a line of best fit, recognizing that the observations (the actual published positions) will generally fall a little-and sometimes a lot-off the line. Outliers may be explained, but they should be understood as outliers.

Since King devotes an entire section ("10.7 Kevin Hoover: a special case") to my views, I trust that using it to illustrate my point will not seem unduly self-indulgent. King reviews virtually everything that I have written about microfoundations since 1988 and somewhat sorrowfully concludes that Hoover

has sharpened his criticism over the years [b]ut has also shifted his ground and has been less than entirely consistent in his opposition to [microfoundations]. His is an instructive case study in how the question of microfoundations can generate some confusion even among the best of its adversaries (p. 218). 
My 1988 book was not concerned with the validity of microfoundations at all, but touched on the subject only incidentally in the attempt to understand the doctrines of the new classical macroeconomics. It was not a work of methodology or of history, but rather what my dissertation adviser referred to as "higher journalism". In later years my interest in microfoundations took both an historical and a philosophical turn. While I do not wish to pretend that my views have not changed and developed, there has, I believe, been a clear consistency in them since the early 1990s. The reason that King is disappointed is that he collapses a variety of texts, spanning a quarter century into a virtual and timeless volume in which each appears as a chapter to be scrutinized for inconsistency with no serious attention to the way in which the succession of views relate to one another, to the different audiences for whom they were written, to the conversational gambits that they employ, to the views of the critics to whom they react, to the gaps I felt necessary to fill in the face of sharp philosophical interlocutors, to my willingness to explore how far views that I disagreed with might in fact be defensible, or to the fact that the issues of microfoundations interact in complex ways with other philosophical projects such as the nature of causation, the role of models in science, the nature of scientific idealization, and the role of intentionality. I would not profess to being perfectly consistent over time-after all, to paraphrase Keynes, when I get new information I reconsider my views ("what do you do?" Keynes added). Nor would I profess to being perfectly consistent at any time-who is? But I do think, to use Patinkin's metaphor, that either a cross-sectional or time-series regression line for my views would show a relatively low standard error.

In applying his defective historiographic method to my views, King does no real damage to his overall case: after all, King and I more or less play for the same side. But in applying his method to the microfoundationalists he weakens his case as only an uncharitable and unsympathetic critic can. Good history, like a good novel, requires an author to make an imaginative transposition, to try to occupy the point of view of the historical actors. King never really gets inside the head of people like Robert Lucas or Edward Prescott to see why the microfoundations dogma appeals to them. He is content, for example, to observe that Lucas "made little or nothing of microfoundations in his major articles of the early 1970s to mid-1970s" (p. 103). As history, this is bizarre. Lucas and Leonard Rapping's work on labor markets in 
the late 1960s was, on their own telling, part of the program of Klein and the econometricians to provide microeconomic underpinnings to the main aggregate functions in the Keynesian macromodels. It was in that context that Lucas introduced rational expectations into mainstream macroeconomics, which in turn, partly for technical reasons, encouraged the adoption of market-clearing, generalequilibrium models as the framework for the analysis. His most famous paper, published in the Journal of Economic Theory in 1972, was an attempt to provide a microeconomic model of aggregate supply or the Phillips-curve phenomenon. It used Phelps's search-theoretic "island model", a model that was a centerpiece of the famous "Phelps volume", Microeconomic foundations of employment and inflation theory (1970). That King sees Lucas as having "made little or nothing of microfoundations" is testament to his having been boxed in by his own approach to view only representative-agent, rational expectations models as a true expression of microfoundations.

Not only does King not mention Lucas's paper in the Journal of Economic Theory, he does not discuss the most central paper in the new classical microfoundations literature, Lucas's "Econometric policy evaluation: a critique" (1976). It is that paper that provides the fundamental rationale for microfoundations after 1970. Lucas argues that Keynesian econometric models are bound to show structural breaks when used to inform policy because they are aggregative, and that only a model that is grounded in the invariants of taste and technology-that is, in the behavior and constraints of individual agents-will be stable in the face of shocks or will be capable of supporting counterfactual policy analysis. Every new classical or new Keynesian microfoundational model-at first, explicitly but eventually only implicitly-is justified in the minds of its advocates as an attempt to avoid Lucas's criticism. This is the linchpin of the history of microfoundations, yet King mentions the "Lucas critique" only obliquely, in a discussion of Mark Blaug. One might attack the Lucas critique or its relevance in various ways, but to ignore it in an account of microfoundations is to misunderstand the principal appeal of microfoundations to contemporary economists.

\section{V}

Perhaps I have been overly negative. King has done a monumental job of absorbing vast and diverse literatures. There is much to be learned in his book. I just cannot help thinking that a more sympathetic and 
flexible approach would ultimately have produced a more valuable book and supported a more compelling argument against the microfoundations dogma.

\section{REFERENCES}

Frisch, Ragnar. 1933. Propagation problems and impulse problems in dynamic economics. In Economic essays in honor of Gustav Cassel. London: George Allen and Unwin, 171-205.

Hartley, James E. 1999. The representative agent in macroeconomics. London: Routledge.

Hoover, Kevin D. 1988. The new classical macroeconomics: a sceptical inquiry. Oxford: Blackwell.

Hoover, Kevin D. 2012. Microfoundational programs. In Microfoundations reconsidered: the relationship of micro and macroeconomics in historical perspective, eds. Pedro Garcia Duarte, and Gilberto Lima Tadeu. Cheltenham: Edward Elgar, 19-61.

Janssen, Maarten C. W. 1993. Microfoundations: a critical inquiry. London: Routledge.

Keynes, John Maynard. 1936 The general theory of employment, interest, and money. London: Macmillan.

Klein, Lawrence R. 1947. The Keynesian revolution. New York: Macmillan.

Leontief, Wassily. 1936. The fundamental assumption of Mr. Keynes's monetary theory of unemployment. Quarterly Journal of Economics, 51 (1): 192-197.

Lucas, Robert. 1972. Expectations and the neutrality of money. Journal of Economic Theory, 4 (2): 103-124.

Lucas, Robert. 1976. Econometric policy evaluation: a critique. In The Phillips Curve and labor markets, eds. Karl Brunner, and Alan Meltzer. Carnegie-Rochester Conference Series on Public Policy, vol. 1. New York: Elsevier, 19-46.

Phelps, Edmund S. (ed.). 1970. Microeconomic foundations of employment and inflation theory. New York: Norton.

Weintraub, E. Roy. 1977. The microfoundations of macroeconomics: a critical survey. Journal of Economic Literature, 15 (1): 1-23.

Weintraub, E. Roy. 1979. Microfoundations: the compatibility of microeconomics and macroeconomics. Cambridge: Cambridge University Press.

Kevin D. Hoover is professor of economics and philosophy at Duke University. He is the author of Causality in macroeconomics and The methodology of empirical macroeconomics. He is a past editor of the Journal of Economic Methodology and current editor of History of Political Economy.

Contact e-mail: <kd.hoover@duke.edu> 